\title{
PENENTANGAN MASYARAKAT MURUT DALAM PERANG RUNDUM: FAKTOR DAN BENTUK PENENTANGAN (1909-1915)
}

\section{MURUT COMMUNITY RESISTANCE DURING RUNDUM WAR: FACTORS AND FORMS OF RESISTANCE (1909-1915)}

\author{
Nur Adira Binti Aratin ${ }^{1}$, Maureen De Silva ${ }^{2}$ \\ ${ }^{1-2}$ Fakulti Sains Sosial dan Kemanusiaan di Universiti Malaysia Sabah \\ Email: 1adira_ra@yahoo.com, ${ }^{2}$ maureend@ums.edu.my
}

\begin{abstract}
This article discusses the resistance of the Murut community in the Rundum War during the administration of the British North Borneo Company (BNBC) from 1909 to 1915. Specifically, this study attempts to analyze the factors of resistance, and the form of resistance used by the Murut community in the Rundum War to oppose foreign colonialism in the Rundum Interior. This study relies heavily on the use of primary sources, especially the BNBC documents such as the British North Borneo Herald $(\mathrm{BNBH})$ newspapers and colonial papers under the Colonial Office (CO) records and the North Borneo Central Archives (NBCA) collection. In addition, secondary sources such as books and articles were also utilised. The paper reveals that the factors of Murut resistance differ according to the perception of the Murut community itself and from the perspective of the colonialists. For the Murut community, the main factor was due to the cultural clash between the Murut community and the BNBC, and they opposed the actions of the BNBC which disrupted their social, economic and political life. For the BNBC, the Murut resistance was seen as an attempt to oppose change and modernization, and to maintain a primitive lifestyle and the absence of law. The form of resistance of the Murut community in the Rundum War has undergone changes from unarmed resistance (1909 to 1914) to a more radical resistance (February-April 1915) by taking up arms to form a Murut nation, free from colonial grasp.
\end{abstract}

Keywords: Murut Society, Rundum War, British North Borneo Company. 


\begin{abstract}
ABSTRAK
Artikel ini membincangkan penentangan masyarakat Murut dalam Perang Rundum semasa era pentadbiran British North Borneo Company (BNBC) pada tahun 1909 sehingga tahun 1915. Secara khususnya kajian ini cuba menganalisis faktor penentangan masyarakat Murut dalam Perang Rundum di samping menjelaskan bentuk penentangan yang dilakukan oleh masyarakat Murut bagi menentang penjajahan kuasa asing di kawasan Pedalaman Rundum. Kajian ini banyak bergantung kepada penggunaan sumber primer terutamanya dokumen BNBC seperti akhbar British North Borneo Herald $(B N B H)$ dan dokumen kolonial di bawah koleksi Colonial Office (CO) dan North Borneo Central Archives (NBCA). Selain itu, sumber sekunder seperti buku dan artikel juga turut digunakan dalam kajian ini. Kajian ini mendapati bahawa faktor penentangan Murut berbeza mengikut persepsi masyarakat Murut itu sendiri dan dari perspektif pihak penjajah. Bagi masyarakat Murut, faktor utama penentangan mereka adalah disebabkan berlakunya pertembungan budaya antara masyarakat Murut dengan pihak BNBC, dan mereka menentang tindakan pihak BNBC yang mengganggu kehidupan sosial, ekonomi dan politik mereka. Bagi pihak BNBC, penentangan Murut dianggap sebagai suatu usaha menentang perubahan dan arus permodenan, dan ingin mengekalkan kehidupan asal yang primitif dan ketiadaan undang-undang. Bentuk penentangan masyarakat Murut dalam Perang Rundum pula telah melalui perubahan yakni dari penentangan tidak bersenjata (1909 hingga tahun 1914) kepada penentangan yang lebih radikal (Februari-April 1915) dengan mengangkat senjata untuk membentuk satu nasion Murut yang bebas dari cengkaman penjajah.
\end{abstract}

Kata Kunci: Masyarakat Murut, Perang Rundum, British North Borneo Company

\title{
Pengenalan
}

Makalah ini membincangkan tentang penentangan masyarakat Murut dalam Perang Rundum semasa era pentadbiran Btistih North Borneo Company (BNBC) di Borneo Utara. Kajian ini memberi penekanan utama kepada faktor penentangan masyarakat Murut dalam Perang Rundum dan bentuk penentangan yang berlaku. Semenjak pertapakan BNBC di bahagian Pedalaman Rundum pada tahun 1909, sering kali berlaku penentangan yang melibatkan masyarakat Murut dengan BNBC. Penentangan yang berlaku membawa kepada konflik bersenjata atau lebih tepat lagi Perang Rundum. 
Perang Rundum merujuk kepada penentangan masyarakat Murut terhadap pihak BNBC yang berlaku di bahagian Pedalaman Rundum. Perang Rundum berlaku pada tahun 1915 namun fasa-fasa awal bermulanya konflik MurutBNBC adalah pada tahun 1909 iaitu melalui kebangkitan penentangan yang diketuai oleh Linggam dan Melayak (British North Borneo Herald, 1 April 1909:73).

Perang Rundum 1915 telah memperlihatkan penyatuan masyarakat Murut yang sebelum ini terkenal dengan sejarah permusuhan antara suku kaum (R.M. Jasni, 2012:39). Penyatuan ini menunjukkan bahawa tindakan yang dilakukan oleh pihak BNBC terhadap masyarakat Murut di bahagian Pedalaman Rundum bukan perkara yang biasa bagi masyarakat Murut. Hal yang demikian kerana masyarakat Murut menganggap bahawa pentadbiran BNBC telah menganggu aspek sosial, ekonomi dan politik mereka. Namun, bagi pihak BNBC pula, tindakan masyarakat Murut yang menentang pentadbiran BNBC dianggap sebagai menolak arus perubahan dan pemodenan yang dilakukan oleh BNBC. Seiring dengan penentangan masyarakat Murut terhadap BNBC, bentuk penentangan mereka juga telah mengalami perubahan iaitu dari penentangan secara tidak bersenjata kepada penentangan yang lebih radikal.

\section{Sorotan Literatur}

R.M Jasni (2012) dalam karyanya Ontoros Antanom Mempertahankan Kemerdekaan Negeri Murut dan Binson A. Sabiah melalui karyanya iaitu Pahlawan Murut Ontoros Bin Endai@Antenom merupakan buku penting mengenai kebangkitan penentangan yang dilakukan oleh masyarakat Murut di Rundum daripada perspektif masyarakat tempatan. Peristiwa-peristiwa sejarah mengenai perjuangan masyarakat Murut banyak ditekankan dalam buku ini dan dikatakan bahawa perjuangan masyarakat Murut telah bermula pada tahun 1909 lagi. Kedua-dua kajian ini juga menjelaskan tentang pengenalan awal masyarakat Murut dan mengistilahkan kawasan pedalaman yang tidak pernah ditadbir oleh mana-mana kuasa sebagai 'Negeri Murut'. Antanom pula dinyatakan sebagai pahlawan Murut yang telah mengetuai masyarakat Murut untuk merancang penentangan terhadap pihak BNBC. Oleh itu, kajian ini penting untuk mengetahui peristiwa-peristiwa perjuangan masyarakat Murut menentang pihak BNBC dari perspektif masyarakat tempatan. 
Ian Black (1982) dalam artikelnya iaitu The Rudum Rebellion of 1915 in Sabah: Millenarianism and Social Protest menyentuh secara terperinci mengenai secara latar belakang berlakunya Perang Rundum. Pertapakan pihak BNBC di Borneo Utara pada tahun 1883 telah menyebabkan kebanyakkan masyarakat memberontak dan menolak pentadbiran BNBC di Borneo Utara. Ian Black turut membincangkan hubungkait antara pentadbiran BNBC sebelum pemberontakan dan dasar-dasar pentabiran BNBC yang membawa kepada kebangkitan penentangan masyarakat Murut pada tahun 1915 dan mengidentifikasikan Antanom sebagai millinearian leader kerana berjaya menyatupadukan suku kaum Murut yang terkenal dengan sejarah permusuhan antara suku kaum .

Selain itu, Callistus Fernandez (1999), Callistus Fernandez (2000) dan Cecillia Leong (1982) membincangkan tentang faktor berlakunya Perang Rundum. Menurut Cecilia Leong, faktor yang menyebabkan berlakunya Perang Rundum adalah disebabkan oleh pelaksanaan cukai minuman keras, cukai ladang, bridle path work dan pengaruh dari pihak luar. Callistus Fernandez (1999) dan Callistus Fernandez (2000) pula menegaskan bahawa penentangan yang dilakukan oleh masyarakat Murut disebabkan oleh campur tangan pihak BNBC dalam kehidupan sosial, budaya, ekonomi dan politik mereka. Dasar campur tangan BNBC telah menganggu norma sosial masyarakat Murut. Di samping itu, Callistus Fernandez (2000) turut menyentuh faktor penentangan masyarakat Murut dari perspektif BNBC.

Dayu Sansalu (2019) dalam artikelnya yang bertajuk Ontoros@Antenom Pahlawan Terbilang Bangsa Murut di Sabah menyatakan bahawa Antanom menentang penjajah BNBC adalah untuk mempertahankan hak kedaulatan tanah airnya daripada diceroboh. Masyarakat Murut menganggap pihak BNBC tidak bertanggungjawab apabila BNBC memperkenalkan dasar baharu tanpa menghiraukan adat, budaya dan kepercayaan masyarakat Murut. Misalnya, menceroboh kawasan hutan yang bertujuan untuk membina jalan rentas. Bagi masyarakat Murut, tindakan tersebut menganggu roh nenek moyang mereka. Ironinya, dasar baharu yang diperkenalkan oleh pihak BNBC menindas kaum Murut dan menganggu.

Bukan itu sahaja, Siti Aidah Hj. Lokin (2007) pula menyatakan bahawa perubahan dasar pentadbiran, ekonomi dan sosial yang dilaksanakan oleh pihak BNBC di kawasan Pedalaman Rundum telah menyebabakan ketidakpuasan hati masyarakat Murut. Hal yang demikian kerana masyarakat 
Murut menganggap bahawa perubahan yang dilakukan oleh BNBC telah menggugat adat dan nilai estetika masyarakat Murut.

\section{Kaedah Kajian}

Kaedah kajian yang digunakan adalah mengikut disiplin sejarah. Kajian ini dilakukan berasaskan kepada kajian kualitatif. Kaedah kajian yang diguna pakai dalam menjalankan penyelidikan ini adalah dengan merujuk kepada sumber primer yang terdapat di Arkib Negeri Sabah. Sumber dapatan utama kajian ini adalah berdasarkan fail-fail semasa pemerintahan BNBC ke atas Borneo Utara seperti British North Borneo Herald (BNBH), North Borneo Central Archive (NBCA) dan Colonial Office (CO) records dari tahun 1909 hingga tahun 1915. Kesemua bahan dan dokumen tersebut adalah yang terpilih berdasarkan skop tahun kajian dan kod-kod tertentu. Misalnya, akhbar BNBH 1909, 1913, 1914 dan 1915, fail NBCA 284 Ladang Ordinance Proclamation 1913, 1178 Native Liquors Taxation dan Public Record Office C.O 874/794, C.O 874/834. Untuk menseimbangkan rekodrekod kolonial, sumber sekunder juga aspek penting dalam kajian ini. Sumber sekunder ini penting bagi menyeimbangkan sejarah lisan masyarakat Murut dengan rekod-rekod kolonial yang terdapat dalam sumber primer. Kajian ini menggunakan buku yang terdapat di Perpustakaan Penyelidikan Borneo Tun Haji Mohd Fuad Stephens dan Perpustakaan Universiti Malaysia Sabah (UMS). Jurnal terpilih seperti Jurnal dari Perpustakaan Yayasan Sabah dan Akademika 54 turut digunakan bagi mengukuhkan hujah. Antara rujukan utama sumber sekunder kajian ini adalah melalui penulisan Callistus Fernandez, Binson A. Sabiah dan R.M. Jasni. Bukan itu sahaja, kajian lapangan turut dilakukan. Temubual dijalankan bersama dengan Amambil bin Andikur, Yansuku bin Empak dan Daud Oanggerek bin Anggi.

\section{Hasil dan Perbincangan}

\section{Latar Belakang Perang Rundum (1909-1915)}

Perpindahan stesen pangkalan BNBC dari Tomani ke Rundum pada tahun 1909 menyebabkan pihak BNBC memperkenalkan beberapa dasar baharu di bahagian Pedalaman Rundum. Antara dasar yang diperkenalkan adalah kerahan tenaga, cukai minuman keras dan pengenalan Ordinan Ladang 1913 yang mengenakan cukai ke atas pembukaan tanah baru dan kerahan tenaga yang dilakukan oleh pihak BNBC. Dasar yang diperkenalkan ini 
bertentangan dengan norma sosial masyarakat Murut. Pertama, minuman keras seperti tapai dan bahar adalah penting dalam setiap majlis yang diadakan oleh masyarakat Murut. Kedua, pengenalan Ordinan Ladang 1913 telah menghadkan pembukaan tanah baru untuk kegiatan pertanian pindah masyarakat Murut (Callistus Fernandez, 2000:84-85). Hal ini jelas menyebabkan sebahagian besar masyarakat Murut tidak berpuas hati dan melakukan penentangan. Penentangan masyarakat Murut yang pertama berlaku pada tahun 1909 melalui gabungan pasukan yang dipimpin oleh Melayak selaku ketua suku kaum Murut bersama dengan Linggam iaitu pahlawan Murut. Walaupun, kedua-dua pasukan ini bergabung namun mereka gagal mengatasi pihak BNBC apabila Linggam telah ditangkap oleh pihak BNBC manakala Melayak pula ditembak mati dalam operasi pantas pasukan polis British pada tahun 1909. Dalam laporan British North Borneo Herald (1909:73), selepas kematian Melayak pada tahun 1909, tidak ada lagi kebangkitan penentangan yang dilakukan oleh masyarakat Murut melainkan protes dan penolakan terhadap dasar baharu yang diperkenalkan oleh pihak BNBC.

Walau bagaimanapun, pada Jun 1914 gerakan penentangan bangkit semula. Penentangan ini diketuai oleh Blayong iaitu ketua suku kaum Murut Tagol. Kebangkitan penentangan Blayong disebabkan ketidakpuasan hati terhadap BNBC yang mengarahkan penduduk kampungnya membina jalan rentas secara paksa. Pada ketika itu, BNBC mengarahkan ketua-ketua suku kaum Murut menyediakan buruh paksa mengikut giliran (R.M. Jasni, 2012:36). Namun, mereka agak keberatan untuk mematuhi arahan. Kegagalan masyarakat Murut mematuhi arahan pihak BNBC akan menyebabkan mereka dikenakan hukuman penjara (Binson A. Sabiah, 2004:27). Oleh itu, mereka terpaksa membina jalan rentas yang menghubungkan Rundum dan Pensiangan. Akibat rasa tidak puas hati, Blayong dan anak-anak buahnya telah melarikan diri semasa pembinaan jalan rentas. Semasa tempoh tersebut, Blayong umpama pelarian. Hal ini kerana beliau sentiasa dijejaki oleh BNBC. Sesiapa yang bertindak melindungi Blayong akan dikenakan hukuman. Misalnya, tindakan ketua suku kaum Murut di Selalir iaitu Siluang yang melindungi Blayong menyebabkan beliau diberikan hukuman oleh pihak BNBC. Rumah Siluang dibakar dengan alasan rumah tersebut merupakan tempat perlindungan orang-orang yang menentang pihak BNBC (Binson A. Sabiah, 2004:30). Di samping itu, pihak BNBC juga memberi ugutan kepada Blayong hingga menyebabkan Blayong bersetuju untuk tunduk terhadap pentadbiran BNBC. Penyelesaian yang diberikan oleh Blayong menyebabkan BNBC 
beranggapan bahawa masalah ini telah diatasi (Callistus Fernandez, 2000:79). Namun begitu, tanggapan pihak BNBC tidak tepat.

Dengan keyakinan untuk mencapai kejayaan, masyarakat Murut melancarkan penentangan bersenjata pada Februari-April 1915 yang dipimpin oleh Antanom. Penentangan bersenjata ini membawa kepada Perang Rundum 1915. Ian Black (1981:7) menyatakan bahawa semasa peperangan ini, anggaran seramai 1000 orang Murut dari suku kaum Murut Tagol yang tinggal di sepanjang Sungai Selalir, Selatan Sungai Sembakung, Sungai Tagol, Sungai Talankai, Sungai Rundum, Sungai Sapulut, Sungai Mesopo, Sungai Dalit, Sungai Bangawan, Sungai Siliu dan Sungai Telekosan telah bersatu untuk menyertai peperangan menentang pihak BNBC. Mereka telah membina kubu pertahanan di Silangit yang memakan masa selama dua tahun bermula dari tahun 1913 hingga tahun 1915 (daripada temubual penulis dengan informan). Antanom dan pengikutnya memulakan serangan pertama pada Februari 1915 dengan menyerang pangkalan BNBC di Pensiangan. Pada masa yang sama, terdapat juga pasukan Antanom yang menyerang N.B Babaneou iaitu pegawai daerah pedalaman serta pasukan polisnya semasa mereka sedang dalam perjalanan ke stesen pangkalan di Pensiangan.

Seterusnya pada 6 Mac 1915, Antanom dan pasukannya sekali lagi menyerang BNBC di stesen pangkalan Rundum. Menurut Owen Rutter (2008:221-222) dan Cecillia Leong (1982:158), insiden serangan ini menyebabkan W. L. Bunbury iaitu Residen BNBC yang ditugaskan di kawasan Pedalaman memberi perhatian lebih terhadap kawasan Rundum. Beliau telah menghantar seangkatan pasukan polis yang terdiri daripada 50 anggota dan beberapa anggota perisik Dayak ke Rudum. P.H Pearson iaitu ketua polis pedalaman berserta dengan 15 anggota polis sepoi berbangsa India turut dihantar ke Rundum untuk membantu N.B Babaneou mematahkan serangan masyarakat Murut (Sabah Times, 4 Mei 1995:5). Pada 9 April, W. L. Bunbury, P. H. Pearson, Tabuteau iaitu pakar senjata dari Cape Mounted Riffles dan 95 anggota polis yang terdiri daripada 15 orang polis India, 10 Orang polis tempatan, 70 orang polis Dayak dan 300 orang pengangkat barang yang terdiri daripada masyarakat tempatan telah menuju ke kubu Antanom di Silangit dengan tujuan untuk menamatkan penentangan Murut.

Pada 13 April, pasukan ini tiba di kawasan yang berhampiran dengan kubu Antanom. Pada 14 April, serangan pertama ke atas kubu Antanom telah dilancarkan. Namun begitu serangan pertama ini gagal menembusi kubu 
Antanom. Di samping itu, pihak BNBC juga gagal mengesan kedudukan pintu masuk kubu Antanom (Callistus Fernandez, 2000:80, R.M. Jasni, 2012:65). Serangan demi serangan yang dilancarkan menyebabkan Antanom dan pasukannya membalas serangan BNBC. Walau bagaimanpun, masyarakat Murut telah mengalami kekalahan dalam peperangan ini (Owen Rutter, 2008:222). Terdapat beberapa faktor yang menyebabkan kekalahan masyarakat Murut:

a) Pemotongan saliran air ke dalam kubu Antanom yang menyebabkan ramai pengikut Antanom mati kelaparan kerana bekalan makanan dan bekalan air bersih tidak dapat disediakan.

b) Antanom dan pengikutnya tidak mempunyai kemudahan dan kelengkapan senjata seperti mana yang di miliki oleh pihak BNBC. Mereka masih lagi menggunakan senjata tradisional seperti lembing, damak, pailang, sumpitan dan senapang Kepin berbanding dengan pihak BNBC yang menggunakan senjata modern.

c) Pengkhianatan orang dalam di mana terdapat masyarakat Murut sendiri yang berkerja dengan pihak BNBC.

\section{Faktor Penentangan Masyarakat Murut dalam Perang Rundum}

Seperti yang dinyatakan, faktor utama penentangan masyarakat Murut dalam Perang Rundum adalah disebabkan berlakunya pertembungan budaya antara masyarakat Murut dengan BNBC. Tindakan BNBC yang memperkenalkan beberapa dasar baharu di bahagian Pedalaman Rundum tanpa mengambil kira tentang amalan, adat dan tradisi masyarakat Murut telah menyebabkan berlaku pertembungan budaya di antara masyarakat Murut dengan BNBC. Dasar baharu seperti kerahan tenaga, Ordinan Ladang 1913, pengenalan cukai minuman keras amat bercanggah dengan apa yang diamalkan oleh masyarakat Murut di kawasan Rundum. Pengenalan Ordinan Ladang 1913 telah menghadkan pembukaan pertanian pindah masyarakat Murut. Hal ini menyebabkan budaya masyarakat Murut yang suka berpindah randah menjadi sukar. Dalam masa yang sama, pengenalan cukai minuman keras juga telah menganggu budaya dan cara hidup masyarakat Murut. Kebebasan masyarakat Murut untuk menghasilkan dan memperolehi minuman keras sebelum ini tidak pernah diganggu oleh pihak luar sehingga berlaku campurtangan BNBC untuk mengenakan cukai terhadap minuman keras. Oleh itu, masyarakat Murut menganggap bahawa pembukaan pangkalan BNBC di Rundum adalah sebagai suatu bentuk pencerobohan penjajah dan menganggu kehidupan sosial, ekonomi dan politik mereka seperti mana yang dijelaskan oleh K. G. Tregonning (1965:210): 
... for centuries had lived their self-sufficient lives hostile to everyone, were slowly combining against this strong outside preasure which was affecting a complete reversal at their lawless customs...

Sebelum pendudukan BNBC di bahagian Pedalaman Rundum, masyarakat Murut merupakan satu bangsa pahlawan yang amat disegani. Namun selepas kedatangan BNBC, masyarakat Murut tidak lagi menjadi bangsa pahlawan yang disegani tetapi status mereka telah bertukar kepada angkatan buruh (Callistus Fernandez, 2000:85). Mereka diarahkan menjadi buruh dalam pembinaan jalan rentas, penyambungan kawat telegraf dan pengangkat barang. Kerahan tenaga ini pemangkin kemarahan masyarakat Murut terhadap BNBC kerana mereka bukan sahaja tidak diberikan upah yang setimpal dengan kerja yang dilakukan tetapi kerja pembinaan jalan rentas juga menimbulkan kesengsaraan kepada masyarakat Murut. Menurut R.M. Jasni (2012:58), kaum lelaki dipaksa untuk meninggalkan keluarga semasa tempoh pembinaan jalan rentas tersebut. Hal ini menyebabkan keluarga yang ditinggalkan mengalami kekurangan makanan kerana tempoh masa yang lama untuk menyiapkan jalan rentas. Kaum lelaki yang biasanya berkerja, tidak dapat lagi bercucuk tanam. Gambaran kerja-kerja pembinaan jalan rentas ini dapat dilihat melalui Akhbar British North Borneo Herald yang bertarikh 16 Julai 1913:127.

During the month construction on the new path has been got well in hand. Antakul 120 chains, Raut 40 chains, Sayong 40 chains and Ulal 40 chains have finished their divisions. Ampau and Inong have done 20 and 40 chains respectively of theirs. The path is being cut 3 feet and is now rideable for $31 / 2$ miles.

Seterusnya, pengenalan Ordinan Ladang 1913 juga menyebabkan ketidakpuasan hati masyarakat Murut. Ordinan ini menghadkan pembukaan tanah baru dan melarang masyarakat Murut menebang hutan untuk tanaman sementara kecuali mereka membayar $\$ 0.50$ sen untuk satu ekar tanah yang digunakan. Tambahan pula, denda sebanyak \$25.00 akan dikenakan keatas sesiapa sahaja yang tidak mematuhi ordinan yang telah ditetapkan dan manamana individu yang menebas hutan tanpa permit daripada pihak BNBC akan dipenjarakan selama enam bulan (284, Ladang Ordinance Proclamation 1913:1-3). Pengenalan Ordinan ini menyebabkan masyarakat Murut tidak dapat lagi mengamalkan pertanian tradisi mereka kerana mereka dilarang untuk berpindah-randah setiap musim membuka hutan baharu (Callistus 
Fernandez, 2000:85, R.M Jasni, 2012:51). Ordinan ini diperkenalkan oleh Gabenor Parr selaku Gabenor Borneo Utara. Tujuan Gabenor Parr memperkenalkan ordinan ini adalah untuk melarang sebarang aktiviti pembersihan hutan dan pertanian pindah yang menyebakan kerosakkan hutan primer (Cecillia Leong, 1982:152). Pihak BNBC beranggapan bahawa pengenalan ordinan ini adalah untuk menghadkan kemusnahan hutan primer. Walau bagaimanapun, masyarakat Murut menganggap bahawa ordinan ini bertentangan dengan budaya masyarakat Murut kerana menghalang mereka bertanam padi bukit. Masyarakat Murut tidak dapat menebas hutan dan berpindah-randah untuk mencari kawasan tanah yang subur. Kegiatan tradisi yang tidak dapat dijalankan menyebabkan masyarakat Murut bangkit menentang BNBC.

Di samping itu, sistem pencukaian yang dikuatkuasakan juga telah menambah kemarahan masyarakat Murut. Cukai yang dikenakan menyebabkan masyarakat Murut tidak dapat melaksanakan adat, tradisi dan budaya mereka. Sistem pencukaian juga telah merubah sistem ekonomi tradisional masyarakat Murut kerana sebelum ini masyarakat Murut tidak terlibat dengan sistem ekonomi yang melibatkan wang (Callistus Fernandez, 2000:85). Misalnya, cukai minuman keras yang diperkenalkan menyebabkan masyarakat Murut sukar untuk menghasilkan minuman keras. BNBC melaporkan pungutan cukai ini untuk kebaikan masyarakat Murut agar tabiat meminum arak dapat dikurangkan (1178, Native Liquors Taxation:39). Namun masyarakat Murut menganggap bahawa cukai yang dikenakan menganggu budaya dan amalan tradisi masyarakat Murut (R.M. Jasni, 2012:51). Jika diteliti daripada aspek budaya kaum Murut, Tapai dan Bahar adalah minuman tradisi turun temurun mereka. Minuman ini disediakan khas untuk upacara penting seperti kematian, perkahwinan, kelahiran, pesta menuai dan perayaan-perayaan lain (Ian Donal Black, 1981:8, Callistus Fernandez, 1999:92). Oleh itu, apabila Gabenor Parr mewajibkan penduduk membayar cukai ke atas bahan-bahan yang digunakan dalam membuat minuman keras (C.O 874/794, Liquor Ordinance 1914), masyarakat Murut telah bangkit menentang pihak BNBC bagi mempertahankan budaya dan amalan tradisi mereka. Dayu Sansalu (2017:44-47) juga menyatakan bahawa sistem cukai yang diperkenalkan merupakan satu perubahan yang drastik bagi masyarakat tempatan. Hal ini mengubah budaya dan tradisi masyarakat Murut.

Oleh itu, jelas bahawa faktor utama penentangan masyarakat Murut dalam Perang Rundum adalah disebabkan berlakunya pertembungan budaya antara masyarakat Murut dengan pihak BNBC. Walau bagaimanapun, bukan 
hanya pertembungan budaya sahaja yang menyebabkan berlakunya Perang Rundum namun faktor-faktor lain seperti faktor ekonomi juga adalah penyebab berlakunya Perang Rundum. Kebanyakkannya dasar-dasar baharu yang diperkenalkan berkaitan dengan ekonomi masyarakat Murut. Hal ini yang membawa perubahan kepada adat dan budaya masyarakat Murut. Walaupun pihak BNBC menganggap penentangan Murut sebagai suatu usaha menentang perubahan dan arus permodenan, dan mahu kekalkan kehidupan asal yang primitif (Callistus Fernandez, 1999:81). Namun Callistus Fernandez (1999:81) juga menyatakan bahawa penentangan masyarakat Murut disebabkan dasar campur tangan pihak BNBC terhadap cara hidup, ekonomi dan politik masyarakat Murut yang membawa kepada pertembungan budaya antara masyarakat Murut dan BNBC. Hal ini dapat dilihat menerusi kehidupan masyarakat Murut sebelum dan selepas pertapakan BNBC di kawasan Pedalaman Rundum. Sebelum pertapakan BNBC, masyarakat Murut merupakan golongan pahlawan yang amat disegani.

Sabihah Osman (1985:11) menyatakan bahawa sebelum pendudukan BNBC di bahagian Pedalaman Rundum, masyarakat Murut mengamalkan sistem politik kesukuan yang mana institusi politik kesukuan hanya melibatkan masyarakat di peringkat kampung kerana mereka hidup dalam kelompok kecil sahaja. Masyarakat Murut sangat mementingkan sistem kekeluargaan (Abd Hadi Borhan, 2016:65). Bukan sahaja susunan politik mereka berdasarkan kepada ikatan kekeluargaan dan sanak saudara tetapi mereka juga digalakkan untuk berkahwin dengan mereka yang sekaum. Menurut Reid. A (1997:120) masyarakat Murut juga mengamalkan cara hidup yang bersifat tradisional iaitu berdasarkan tradisi turun temurun. Kehidupan masyarakat Murut bercorak sara diri iaitu mereka mengamalkan aktiviti penanaman padi bukit (huma), pertanian pindah, penternakan dan memungut hasil hutan. Setiap keluaraga mengamalkan sistem pertanian pindah (Jacquline Pugh-Kitingan, 2012:61) dan minuman keras seperti Tapai dan Bahar adalah minuman tradisi turun temurun yang disediakan khas untuk upacara penting seperti upacara perkahwinan, pesta menuai, kematian dan perayaan-perayaan lain.

Namun pertapakan BNBC membuka lembaran baru kepada masyarakat Murut. Sistem politik kesukuan berubah kepada sistem pentadbiran yang berasaskan dasar BNBC (Chung Jeak Fuan, 2019:39). BNBC mula mengenakan cukai ke atas penduduk dan memaksa setiap ketua suku menyediakan buruh bagi membina jalan rentas yang dapat menghubungkan satu daerah dengan daerah yang lain. Cukai yang dikenakan 
oleh pihak BNBC menyebabkan masyarakat Murut tidak dapat meneruskan tradisi pertanian pindah dan penyediaan minuman keras. Dasar-dasar ini menyebabkan berlaku pertembungan budaya antara masyarakat Murut dan BNBC yang akhirnya membawa kepada Perang Rundum 1915.

\section{Bentuk Penentangan Masyarakat Murut}

Kebangkitan kesedaran masyarakat Murut terhadap penjajahan BNBC di bahagian Pedalaman Rundum dianggap sebagai suatu bentuk pencerobohan penjajah ke atas Negeri Murut ${ }^{1}$ seperti mana yang dijelaskan oleh K. G. Tregonning: The Murut never submitted to the Company, and there was a clear understanding that the government would respect their independent telah menyebabkan bentuk penentangan masyarakat Murut mengalami perubahan. Pada awalnya, bentuk penentangan masyarakat Murut adalah secara tidak bersenjata tetapi telah mengalami perubahan yakni dari penentangan secara tidak bersenjata kepada pendekatan yang lebih radikal dengan mengangkat senjata. Hal ini kerana masyarakat Murut mengalami kebangkitan kesedaran yang ingin membentuk satu nasion Murut yang bebas dari cengkaman penjajah. Perubahan bentuk penentangan ini telah melahirkan perjuangan masyarakat Murut yang lebih mantap.

\section{a. Penentangan Tidak Bersenjata}

Sekitar tahun 1909 hingga tahun 1914 penentangan yang dilakukan oleh masyarakat Murut terhadap BNBC adalah secara tidak bersenjata. Bentuk penentangan yang dilakukan adalah dengan tidak mengakui undang-undang dan arahan yang dikeluarkan oleh pihak BNBC, melarikan diri daripada pihak BNBC serta melakukan protes enggan membayar cukai. Semasa awal pertapakan BNBC di Rundum, mereka telah mendapat penentangan daripada Melayak iaitu salah satu ketua suku kaum Murut di kawasan Pedalaman. Bentuk penentangan yang dilakukan oleh Melayak dan pengikutnya adalah tidak mematuhi arahan dan undang-undang yang dikeluarkan oleh pihak BNBC. Beliau juga banyak menimbulkan masalah terhadap pihak BNBC dan aktiviti-aktiviti yang dilakukan Melayak juga menyebabkan keadaan Rundum dan Sibungo huru-hara seperti yang digambarkan dalam British North Borneo Herald, 1 April 1909:76.

\footnotetext{
1 Menurut R.M Jasni, istilah 'Negeri Murut' diguna pakai oleh masyarakat tempatan di kawasan Pedalaman. Wilayah-wilayah merdeka yang tidak pernah ditadbir oleh Kesultanan Brunei, Kesultanan Sulu mahupun BNBC khususnya di kawasan Pedalaman Pensiangan hanya mengenal kawasan mereka atau kediaman mereka sebagai Negeri Murut. R.M Jasni, Ontoros Antanom Mempertahankan Kemerdekaan Negeri Murut, Kota Kinabalu: Inna Kinabalu Sdn. Bhd, 2012, hlm. 22.
} 
A few days after my arrival the Telecosan headman came in to report raids by Selalir people and further activity Melayak's part: these same people are the cause of the only trouble that has occurred in Rundum and Sibungo during the past two months.

Selain itu, Melayak juga dikatakan telah ditangkap kerena membunuh dan melarikan diri daripada penjara. Hal ini seperti yang dinyatakan dalam British North Borneo Herald, 1 April 1909: 73.

During the past few years repeated efforts have been made to capture Melayak, who, having been arrested for homicide, escaped from goal and has since hurried the villages into supplying himself and followers with food and has resisted the government on every orcusion.

Selepas Melayak berjaya melarikan diri daripada penjara atas tuduhan kesalahan membunuh, beliau menggunakan pengaruhnya selaku ketua suku kaum Murut untuk mendapatkan sokongan dan bantuan daripada penduduk kampung bagi mendapatkan bekalan makanan dan perlindungan namun usaha ini kurang berkesan kerana BNBC telah mengeluarkan arahan untuk menghukum sesiapa sahaja yang bertindak memihak kepada Melayak. Kemudian, penentangan Melayak diteruskan dengan menggabungkan pasukannya dengan pasukan Linggam. Walaupun kedua-dua pasukan ini bergabung namun penentangan Melayak dan Linggam digagalkan oleh BNBC dalam operasi pantas yang dilakukan. Dalam operasi tersebut, Melayak telah ditembak mati dan Linggam berjaya di tangkap (British North Borneo Herald, 1 April 1909:73). Bagi masyarakat Murut, penentangan yang dilakukan adalah tidak melanggar sebarang undang-undang dan peraturan yang dikeluarkan kerana mereka hanya ingin mempertahankan adat, budaya dan kawasan yang mereka diami sejak berkurun lamanya. Perubahan yang mendadak disebabkan oleh pertapakan BNBC tidak dapat diterima oleh masyarakat Murut kerana undang-undang dan peraturan pihak BNBC bukan sahaja menyukarkan kehidupan mereka tetapi keselamatan mereka juga turut terancam (R.M. Jasni, 2012:49).

Selain itu, Blayong dan anak-anak buahnya juga telah melakukan penentangan terhadap pihak BNBC semasa pembinaan jalan rentas. Penentangan Blayong disebabkan rasa tidak puas hati terhadap tindakan BNBC yang memberikan layanan buruk semasa mereka ditugaskan membina jalan rentas. Oleh hal yang demikian, Blayong dan penduduk kampung telah 
meninggalkan tapak pembinaan jalan rentas di Kemabong. Mereka kembali ke kampung halaman dan Blayong telah membina kubu dirumahnya tetapi dengan mudah kubu tersebut dimusnahkan oleh pihak BNBC (Binson A. Sabiah, 2004:29). Akhirnya, Blayong telah melarikan diri hingga ke Selatan Sungai Tagol. Namun pada Jun 1914, Blayong menghantar seorang utusan kepada wakil BNBC yang menyatakan bahawa beliau akan tunduk terhadap pemerintahan BNBC (Ian Black, 1983:226). Hal ini kerana BNBC telah mengeluarkan arahan akan mengenakan hukuman kepada sesiapa yang melindungi dan membantu Blayong.

Bentuk lain penentangan yang dilakukan oleh masyarakat Murut adalah membunuh diri dengan meminum racun tuba. Hal ini dilakukan kerana mereka tidak mahu menjadi buruh paksa kepada pemerintah BNBC dan sebagai tanda penentangan terhadap pentadbiran BNBC di kawasan Pedalaman Rundum. Walau bagaimanapun, bentuk penentangan yang sebegini hanya dilakukan oleh satu hingga tiga orang suku kaum Murut sahaja namun identiti mereka tidak dapat dipastikan kerana ini adalah catatan lisan daripada masyarakat Murut (daripada temubual penulis dengan informan). Pernyataan ini turut disokong oleh R.M. Jasni (2012:37) menurutnya, ada diantara masyarakat Murut Tagol yang sanggup membunuh diri dengan meminum racun daripada menjadi buruh paksa pihak BNBC.

Masyarakat Murut juga melakukan protes dengan tidak membayar cukai. Mengikut undang-undang yang dikeluarkan oleh pihak BNBC, tugas mengutip cukai akan diberikan kepada Native Chief. Sekiranya masyarakat Murut membuat Tapai dan Bahar mereka hendaklah melaporkannya kepada Native Chief agar cukai ke atas bahan yang digunakan dapat dikira. Namun begitu, setiap kali masyarakat Murut membuat Tapai dan Bahar, mereka tidak melaporkan aktiviti tersebut kepada pihak BNBC (1178, Native Liquors Taxation:123-136). Tidak melaporkan aktiviti tersebut adalah sebagai tanda protes menentang BNBC. Memorandum on taxation of Native Liquors melaporkan kutipan cukai dan sikap masyarakat peribumi apabila mereka diarahkan untuk membayar cukai ke atas minuman keras seperti berikut: 
Jadual 1: Laporan Kutipan Cukai dan Sikap Penerimaan Masyarakat Peribumi (1914)

\begin{tabular}{|c|c|c|}
\hline West Coast Residency & Progress & Attitude of Natives \\
\hline $\begin{array}{l}\text { Tenom } \\
\text { (A. B. C. Francis) }\end{array}$ & $\$ 1.50$ collected & $\begin{array}{l}\text { Some paying tax: } \\
\text { absome } \\
\text { strongly resented. }\end{array}$ \\
\hline $\begin{array}{l}\text { Rundum } \\
\text { (N. B. Baboneau) } \\
\text { (per A. B. C. F.) }\end{array}$ & No figures & $\begin{array}{l}\text { Unwilling to submit: exodus } \\
\text { to Dutch Borneo expected. }\end{array}$ \\
\hline
\end{tabular}

Sumber: North Borneo Central Archives, File 1178, Native Liquors Taxation, hlm. 126.

Jadual 1 di atas adalah laporan kutipan cukai dan sikap penerimaan yang ditunjukkan oleh masyarakat peribumi di kawasan Tenom dan Rundum apabila mereka diarahkan untuk membayar cukai minuman keras. Bagi daerah Tenom, terdapat masyarakat yang membayar cukai kepada pihak BNBC dan terdapat juga masyarakat yang menolak untuk membayar cukai. Dari tahun 1913 hingga Februari 1914 hanya sebanyak \$1.50 berjaya dikutip di kawasan Tenom. Walau bagaimanapun, keadaan ini berbeza dengan kawasan Rundum kerana masyarakat Murut di Rundum menolak untuk membayar cukai yang diarahkan oleh pihak BNBC. Oleh itu, jumlah kutipan cukai tidak dapat dinyatakan. Laporan ini memperlihatkan bahawa sejak awal pengenalan cukai minuman keras iaitu pada tahun 1913, masyarakat Murut di bahagian Pedalaman Rundum melakukan penentangan terhadap pihak BNBC. Masyarakat Murut telah melakukan protes dengan tidak membayar cukai sebagai tanda penentangan mereka terhadap pihak BNBC.

\section{b. Penentangan Secara Bersenjata}

Penentangan radikal masyarakat Murut atau dalam erti kata lain iaitu secara bersenjata bermula apabila keinginan untuk bangkit daripada penjajahan pihak BNBC semakin memuncak dalam diri setiap individu suku kaum Murut. Kesengsaraan dan penderitaan yang disebabkan oleh penjajah menyebabkan masyarakat Murut yang sebelum ini di kenali dengan sejarah permusuhan antara suku kaum (R.M. Jasni, 2012:39) atau pemburuan kepala yang sengit antara suku kaum yang berlainan atau rumah panjang yang berlainan (Jacquline Pugh-Kitingan, 2012:26) telah bersatu membentuk satu nasion Murut untuk sama-sama berjuang menentang pihak penjajah (R.M. Jasni, 2012:40, Callistus Fernandez, 1999:99-100). Masyarakat Murut yang terdiri daripada pelbagai suku kaum memilih Antanom sebagai ketua mereka. Pemilihan Antanom sebagai ketua bukan sahaja dikaitkan dengan ciri-ciri pemimpin yang ada dalam diri Antanon tetapi keinginan Antanom sendiri untuk bangkit mengetuai gerakan menentang BNBC di Rundum. 
Pendekatan yang digunakan Antanom dalam menentang BNBC lebih radikal berbanding dengan penentangan yang dilakukan oleh Blayong (1914), Linggam dan Melayak (1909). Penentangan yang dilakukan Antanom lebih tersusun, terancang dan mempunyai visi dan misinya tanpa diketahui oleh pihak BNBC (Callistus Fernandez, 1999:97-100).

Pada tahun 1915, gerakan menentang BNBC yang lebih radikal dimulai dengan mengumpul pasukan Murut. Antanom berjaya mengumpul seramai lebih kurang 1000 orang Murut yang terdiri daripada suku kaum Murut yang tinggal di sekitar kawasan Pedalaman iaitu di sepanjang Sungai Salalir, Selatan Sungai Sembakung, Sungai Tagol, Sungai Sapulut, Sungai Talankai, Sungai Rundum, Sungai Mesopo, Sungai Dalit, Sungai Bangawan, Sungai Telekosan dan Sungai Siliu (C. O. 874/834, Rising in North Keppel and Rundum District 1914-1915). Seterusnya, menurut Dayu Sansalu (2019:30), Antanom dan pengikut-pengikutnya secara senyap membina beberapa kubu seperti kubu Menining di hulu sungai Telekoson, kubu Liohon, kubu Impal dan kubu Salang. Kubu induk dibina di Silangit dengan keluasan tapak boleh menempatkan tujuh buah rumah di dalamnya dan dilengkapi dengan pelbagai kemudahan asas termasuklah terowong bawah tanah.

Bentuk penentangan yang dilakukan Antanom mempunyai persamaan dengan detik-detik perjuangan Tok Janggut di Pasir Puteh, Kelantan dan penentangan Syarif Masahor di Kanowit, Sarawak. Tok Janggut bersama hampir 1000 orang pengikutnya telah menyerang pasukan British di Pasir Puteh, Kelantan (Mohd Bin Samsudin, 2015:9). Begitu juga dengan Syarif Masahor yang telah menyerang kubu James Brooke di Kanowit. Tindakan yang sama juga dilakukan oleh Antanom dan pengikutnya. Pada asasnya, mereka telah memainkan peranan yang sama iaitu pihak yang menyerang. Sebaliknya pihak musuh mereka tidak menduga atau belum bersedia menghadapi serangan tersebut. Namun, perkara utama yang menjadi perbezaan bentuk penentangan ini adalah strategi perang yang dilaksanakan oleh Antanom dan pengikutnya. Mereka melakukan dua siri serangan bersenjata terhadap BNBC yang berpangkalan di Rundum.

Siri serangan hendap yang pertama dilakukan pada 13 Februari 1915. Antanom membahagikan pasukannya kepada dua kumpulan. Kumpulan pertama adalah kumpulan yang menyerang stesen pangkalan BNBC di Pensiangan. Kumpulan ini diketuai oleh Singkunan. Walau bagaimanapun, Singkunan terkorban dalam insiden serangan ini. Kumpulan kedua pula ditugaskan untuk menyerang stesen pangkalan British di Rundum. 
Kumpulan ini diketuai oleh Onsokol. Semasa rombongan Babaneou dalam perjalanan memindahkan stesen pangkalan BNBC dari Rundum ke Pensiangan. Kumpulan ini berjaya menyerang hendap N.B Babaneou dan pasukannya. Cara yang digunakan adalah dengan menyalakan api di sekitar kawasan kedudukan rombongan N.B Babaneou kemudian menyerang musuh menggunakan lembing, sumpitan dan ginsok. Menurut O. G. Ommanney (1935:9), serangan ini telah menyebabkan seorang polis cedera dan seorang budak suruhan Babaneou terkorban. Dalam masa yang sama, pasukan ini juga berjaya memotong kawat telegraf yang menyebabkan sistem perhubungan BNBC di Rundum terputus.

Sehubungan dengan itu, kesempatan ini diambil oleh Antanom untuk menyusun barisan menentang BNBC di stesen pangkalan Rundum. Pada 6 Mac 1915 serangan kedua dilaksanakan. Serangan ini sangat terancang, ia dilakukan pada waktu subuh di mana semua orang dalam keadaan tidak bersedia menghadapi serangan. Serangan ini diketuai sendiri oleh Antanom dengan kekuatan pasukan seramai 600-700 orang dengan menggunakan senjata seperti lembing, damak, pailang, sumpitan dan senapang kepin. Dalam keadaan genting ini, pihak BNBC melancarkan serangan balas yang sengit ke atas pasukan Murut sehinggakan Ismail Abbas dan K. Bali (1985:135) mengambarkan bahawa Rundum bagaikan padang jarak tekukur pada keesokkan harinya. Pertempuran yang berlangsung telah mengakibatkan seramai 12 orang Murut terkorban, 20-30 orang Murut tercedera dan hanya tiga orang sahaja anggota BNBC yang tercedera (Callistus Fernandez, 2000:80). Jumlah korban yang tinggi di kalangan masyarakat Murut dapat dikaitkan dengan kelemahan teknik peperangan dan juga senjata yang digunakan oleh masyarakat Murut tidak dapat mengalahkan senjata yang dimiliki oleh tentera BNBC. Penentangan bersenjata ini sampai kemuncaknya pada April 1915 apabila BNBC menyerang kubu Antanom di Silangit. Walaupun Antanom dan pasukannya menyerang balik pihak BNBC dan berlakunya peristiwa berbalas serangan namun masyarakat Murut kalah dalam peperangan ini. Antanom, Onsukul dan Kalur terkorban dalam peperangan ini.

\section{Penutup}

Kesimpulannya, Perang Rundum berpunca daripada dasar pemerintahan BNBC yang bertentangan dengan budaya, adat istiadat dan cara hidup tradisional masyarakat Murut. Pentadbiran BNBC di Rundum memberi impak yang besar terhadap perubahan sosial masyarakat Murut yang mengakibatkan mereka terikat kepada peraturan dan undang-undang baharu 
yang diperkenalkan. Kerahan tenaga buruh paksa menyebabkan status kepahlawanan masyarakat Murut tercabar. Kerahan tenaga buruh paksa ini dianggap sebagai penindasan kepada masyarakat yang diakui statusnya sebagai sebuah masyarakat yang tidak mudah tunduk terhadap mana-mana pihak. Cukai minuman keras yang diperkenalkan menyebabkan masyarakat Murut tidak dapat mengamalkan budaya dan tradisi mereka yang sangat mementingkan minuman keras dalam upacara-upacara penting seperti perkahwinan, kematian dan perayaan-perayaan yang lain. Kebebasan mereka untuk menghasilkan minuman keras mendapat campurtangan daripada BNBC sehingga mereka terpaksa membayar cukai sebelum menghasilkan minuman keras menyukarkan kelancaran adat dan tradisi mereka dalam pengunaan minuman keras serta merugikan masyarakat Murut. Kewajiban mereka untuk memiliki minuman keras sebagai adat apabila mengadakan suatu perayaan adalah terhad setelah pengenalan cukai minuman keras.

Selain itu, pengenalan Ordinan Ladang 1913 juga telah membangkitkan kemarahan masyarakat Murut. Masyarakat Murut menganggap ordinan ini menghalang budaya pertanian pindah mereka kerana Ordinan Ladang 1913 telah menghadkan pembukaan tanah baru dalam kalangan masyarakat Murut kecuali mereka membayar 0.50 sen untuk satu ekar tanah yang digunakan. Oleh itu, dapat dilihat bahawa dasar baharu yang diperkenalkan oleh pihak BNBC di kawasan Pedalaman Rundum sangat berbeza dengan budaya, adat istiadat dan cara hidup masyarakat Murut. Pengenalan cukai di kawasan Pedalaman juga telah menunjukkan pertembungan budaya antara Murut dengan BNBC. Hal ini demikian kerana sebelum pertapakan BNBC, masyarakat Murut tidak mengamalkan kutipan cukai namun budaya BNBC yang mengamalkan kutipan cukai menyebabkan masyarakat Murut di Rundum diperkenalkan kutipan cukai buat pertama kalinya. Pertembungan budaya inilah yang menjadi faktor utama penentangan masyarakat Murut. Sehubungan dengan itu, bentuk penentangan masyarakat Murut juga telah melalui perubahan iaitu daripada penentangan secara tidak bersenjata kepada penentangan yang lebih radikal. Jika awalnya masyarakat Murut hanya melakukan protes dan penentangan secara tidak bersenjata namun kebangkitan kesedaran masyarakat Murut daripada kesengsaraan dan penderitaan yang disebabkan oleh pertembungan budaya dengan pihak BNBC menyebabkan corak penentangan masyarakat Murut menjadi lebih radikal dengan mengangkat senjata. 


\title{
Rujukan
}

\author{
Akhbar \\ British North Borneo Herald. 1909. 1 April. \\ British North Borneo Herald. 1913. 16 Julai. \\ O. G. Ommanney. A 'Side-Show' in Borneo. The Telegraph, Brisbane. \\ 1935. 1 August. \\ Sabah Times. 1995. 4 Mei.
}

Public Record Office

C. O 874/794, Liquor Ordinance of 1914.

C. O. 874/834, Rising in North Keppel and Rundum District 1914-15, Fraser to Chairman”, 8 September 1915.

\section{North Borneo Central Archives (Pink Files/Secretariat Files)}

284 Ladang Ordinance Proclamation 1913.

1178 Native Liquors Taxation.

Buku / Artikel Jurnal / Bab dalam Buku / Prosiding Persidangan

Abd Hadi Borham, Wahyu Hidayat Abdullah, Mohamad Marzuqi Abdul Rahim dan Muhammad Akramin Kamaruzaman. (2016) Metod Dakwah Mohd Fadhli Yusof dalam Pengislaman Suku Kaum Masyarakat Murut di Pedalaman Sabah. Al-Hikmah 8 (2) 2016: 6080. Retrieve from: http://journalarticle.ukm.my/9945/

Binson A. Sabiah. (2004). Pahlawan Murut Ontoros Bin Endoi@Antenom. Kota Kinabalu: Chin Chi Printing Work Sdn. Bhd.

Black, Ian., (1983). A Gambling Style of Government: The Establishment of Chartered Company Rule in Sabah 1878-1915. New York: Oxford University Press.

Black, Ian., (1981) The Rundum Rebellion of 1915 in Sabah: Millenarianism and Social Protest. Seminar Sejarah Sabah dan Masyarakat Sabah, 12-16 Ogos. Kota Kinabalu: Yayasan Sabah \& Persatuan Sejarah Malaysia.

Callistus Fernandez. (2000). Perkembangan Ekonomi Penjajah dan

Penentangan Masyarakat Murut: Pemberontakan Rundum 1915 dalam Abdul Halim Ali, Ishak Shari, Habibah Ahmad dan Er Ah Choy, Sabah dalam Perluasan Pasaran. Bangi: Penerbit Universiti Kebangsaan Malaysia.

Callistus Fernandez. (Januari 1999). Contesting Colonial Discourse: Rewriting Murut History of Resistance in British North Borneo from 1881 to 1915. Akademika 54: 81-103. 
Dayu Sansalu. (2019). Ontoros@ Antenom Pahlawan Terbilang Bangsa

Murut di Sabah. E-Prosiding Persidangan Antarabangsa Sains Sosial dan Kemanusiaan 2019, eISBN: 978-967-2122-71-5. Selangor: Kolej Universiti Islam Antarabangsa Selangor.

Ismail Abbas dan K. Bali. (1985). Peristiwa-peristiwa Berdarah di Sabah. Kuala Lumpur: Dewan Bahasa dan Pustaka.

Leong, Cecilia., (1982). Sabah: The First 100 Years. Kuala Lumpur: Percetakan Nanyang.

Mohd Bin Samsudin. (2015) Perjuangan Tok Janggut: Satu Realiti Kepada Kebangkitan Nasionalisme. Seminar 100 Tahun Tok Janggut: Arkib Negara Malaysia.

R. M. Jasni, (2012). Ontoros Antanom: Mempertahankan Kemerdekaan Negeri Murut. Kota Kinabalu: Inna Kinabalu Sdn. Bhd.

Reid. A., (1997) Endangered Identity: Kadazan or Dusun in Sabah (Esat Malaysia). Journal of Southeast Asian Studies, 28.

Pugh-Kitingan, Jacqueline. (2012). Kadazandusun. Kuala Lumpur: Institut Terjemahan \& Buku Malaysia.

Rutter, Owen., (2008). British North Borneo An Account of its History, Resources and Native Tribes. Kota Kinabalu: Opus Publication.

Sabihah Osman. (1985). Pentadbiran Bumiputera Sabah 1881-1941. Bangi:

Universiti Kebangsaan Malaysia-Yayasan Sabah.

Siti Aidah Hj. Lokin. (2007). Perubahan Sosioekonomi dan Pentadbiran:

Masyarakat Peribumi Sabah (1881-1963). Kota Kinabalu: Penerbit Universiti Malaysia Sabah.

Tregonning, K, G., (1965). A History of Modern Sabah (North Borneo 18811963). Singapore: University of Malays Press.

\section{Tesis}

Chung Jeak Fuan. (2019). Sejarah Pemberontakan Rundum di Tenom 1910 sehingga 1915. Universiti Malaysia Sabah: Fakulti Kemanusiaan, Seni dan Warisan.

\section{Temubual}

Amambil Bin Andikur. (63 Tahun) dari Kg. Rundum.

Yansuku Bin Empak. (54 Tahun) dari Kg. Rundum.

Daud Oanggerek Bin Anggi. (60 Tahun) dari Kg. Rundum. 